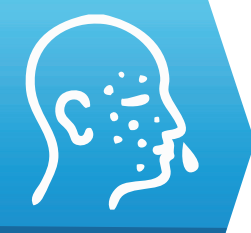

IMUNOLOGY

Immunology-Allergy Department, Adnan Menderes University, Turkey

\title{
Triggering atrial fibrillation after omalizumab injection in a patient with chronic spontaneous urticarial. A case report
}

Songul Cildag

\begin{abstract}
Introduction. Omalizumab is recommended as a third-line treatment in the treatment of chronic spontaneous urticaria. During omalizumab use, which has high efficacy and safety, the side effects observed are usually moderate and temporary. Here we discuss the triggering of atrial fibrillation following omalizumab injection.

Case report. A 72-year-old female patient was treated with omalizumab $300 \mathrm{mg}$ / day due to chronic spontaneous urticaria resistant to conventional treatments. Atrial fibrillation developed 6 hours after the second injection of omalizumab in the patient who had atrial fibrillation and who had been monitored with antiarrhythmic treatment and sinus rhythm for 1 year. The treatment was discontinued because omalizumab was thought to trigger atrial fibrillation, as no other reason to explain the triggering of atrial fibrillation could be found.

Results and conclusion. There is no data in the literature on the use of omalizumab in patients with atrial fibrillation. Different side effects of biological treatments can be observed. In particular, omalizumab should be used with caution in elderly patients and patients with arrhythmia.
\end{abstract}

Keywords: atrial fibrillation, chronic spontaneous urticaria, omalizumab

\section{Introduction}

Chronic spontaneous urticaria is a disease which lasts longer than 6 weeks and can be accompanied by redness, rash, itching and angioedema. The cause of the disease is unknown. At any point in time, it affects $0.5-1 \%$ of the population. It is seen twice as often in women and it reaches its peak incidence between the ages of 20 and $40[1,2]$. The disease usually lasts for 1-5 years, but there are cases that last longer than 5 years [3]. The first option in treatment is second-generation nonsedative $\mathrm{H} 1$-antihistamines and it is recommended to increase the dose by up to 4 times in resistant cases. However, approximately one-third of cases are resistant to H1antihistaminic treatments. Cyclosporine, omalizumab, and montelukast are the third-line treatments in high-dose H1-antihistamine-resistant cases [1]. Omalizumab is a recombinant humanized monoclonal anti-immunoglobulin $\mathrm{E}$ (anti$\operatorname{IgE}$ ) antibody. It binds free $\operatorname{IgE}$ in the circulation, but does not bind the mast cell and $\operatorname{IgE}$ bound on the basophil surface. It leads to the down-regulation of the FceRI (IgE high-affinity receptor) located on the mast cell, basophil and dendritic cell surface by significantly and rapidly reducing the level of free IgE [4]. In 2014, $\mathrm{H} 1$ received a license for adolescents (aged 12 years and over) and adults with chronic spontaneous urticaria (300 mg / day, every 4 weeks) with inadequate response to the antihistamine [5].

Most side effects observed during omalizumab treatment, which has high efficacy and safety, are moderate and transient. The most common side effects are headache, nasopharyngitis, sinusitis, upper respiratory tract infections, injection site reactions, arthralgia, nausea, abdominal pain [6]. It has been reported that postural hypotension and flushing can be observed rarely associated with the cardiovascular system [7]. Also, arterial thrombotic events including stroke, myocardial infarction, angina, ischemic heart disease, acute coronary syndrome and thrombosis are more frequent in patients with treated omalizumab [8]. Literature knowledge about the use of the drug in elderly patients is limited and reliability with the elderly has been shown as well [9]. We present a case of atrial fibrillation triggered by the use 
of omalizumab in an elderly chronic spontaneous urticaria patient with an atrial fibrillation history, who was under antiarrhythmic treatment and followed for sinus rhythm.

\section{Case report}

A 72-year-old female patient was monitored for 1 year for chronic spontaneous urticaria and accompanying angioedema. Her complaints continued despite of high dose antihistaminic treatment and she often needed corticosteroid. She was requested to start omalizumab treatment. In the examinations, whole blood count, liver function tests, renal function tests, serum electrolytes, erythrocyte sedimentation rate, CRP, thyroid function tests were normal and antinuclear antibody, rheumatoid factor, anti-CCP were negative, Hbs Ag, Anti-HCV, AntiHIV was negative, Anti-HBs was positive, stool parasite was negative, hydatid cyst (Elisa $\lg \mathrm{G}$ ) was negative, C3, $\mathrm{C} 4$ were at normal levels. Her history included regular use of propafenone $300 \mathrm{mg}$ / day due to mitral valve prolapse and atrial fibrillation and essitalopram $10 \mathrm{mg} / \mathrm{day}$. She had osteoporosis but was not taking medication. There was no atrial fibrillation in the last 1 year of cardiology follow-up and the patient was monitored for sinus rhythm. Because of the presence of advanced age and atrial fibrillation history, a cardiological evaluation was performed before omalizumab treatment was initiated. Continuation of propafenone treatment was recommended because of antiarrhythmic treatment and sinus rhythm. Propafenone treatment was continued and $300 \mathrm{mg} /$ day omalizumab treatment was initiated for the patient. The patient who had no complications after the first injection and whose complaints had decreased significantly in terms of urticariaangioedema, was treated with omalizumab $300 \mathrm{mg}$ / day for the second dose after 4 weeks. After 2 hours of treatment, the patient was discharged without any complaints. However, complaints of palpitation, fatigue, and dizziness started 6-7 hours after the 2nd injection of omalizumab and the patient checked herself into the emergency department with these complaints. Because of the high ventricular response atrial fibrillation on ECG evaluation, the patient was admitted to the cardiology clinic for treatment. The patient was discharged after the sinus rhythm was observed with the applied antiarrhythmic therapies. There was no intense physical activity story on the same day. When atrial fibrillation developed, she was not using any drugs other than propafenone and essitalopram. Laboratory data included myoglobin $16.97 \mathrm{ng} / \mathrm{ml}(0-110)$, troponin 0.001 $\mathrm{ng} / \mathrm{ml}$ (0-0.06), creatine kinase (CK) $20.3 \mathrm{IU} / \mathrm{L}(0-145)$, CK-MB $0.87 \mathrm{ng} / \mathrm{ml} \mathrm{(0-6),} \mathrm{serum} \mathrm{creatinine} 0.59 \mathrm{mg} / \mathrm{dl}$ (0.5-0.9), blood urea nitrogen $17 \mathrm{mg} / \mathrm{dL}$ (7-20), calcium $8.26 \mathrm{mg} / \mathrm{dL}(8.8-10.6)$, sodium $139.2 \mathrm{mmol} / \mathrm{L}(135-146)$, potassium $4.18 \mathrm{mmol} / \mathrm{l}$ (3.5-5.2), AST $19.38 \mathrm{IU} / \mathrm{L}(0-$ 35), ALT 18.01 IU/L (0-55), LDH 170.1 IU/L (0-247), hemoglobin $14.0 \mathrm{~g} / \mathrm{dl}$, white blood cell count $10.78 \times 10^{3 /}$ $\mathrm{ml}$, platelet count $315 \times 10^{3} / \mathrm{ml}$. Echocardiography revealed: left atrium size $4.2 \mathrm{~cm}$, end diastolic left ventricular cavity size $4.5 \mathrm{~cm}$ with a $60 \%$ left ventricular ejection fraction, normal left ventricular systolic function, bi-leaflet mitral valve prolapse with mild mitral regurgitation, pulmonary artery systolic pressure $45 \mathrm{mmHg}$ with mild-moderate tricuspid regurgitation, right atrium size $3.7 \mathrm{~cm}$, normal right ventricular function.

It was hypothesized that omalizumab could induce atrial fibrillation because of the high ventricular response atrial fibrillation that developed 6 hours after the omalizumab injection. No other cause to trigger atrial fibrillation in a patient with atrial fibrillation history was identified and the patient's antiarrhythmic treatment and sinus rhythm was monitored for 1 year. For this reason, omalizumab treatment was discontinued for this patient.

\section{Discussion}

Omalizumab is well tolerated and is an effective therapy for patients with chronic urticaria. Side effects are mostly moderate and transient [6]. Rare cases of anaphylaxis have been reported with an incidence around $0.2 \%[10]$. The most frequent side effects are injection site skin reactions and also urticaria, fever, headache, nasopharyngitis, abdominal pain, nausea, dyspeptic complaints, flu-like syndrome, fatique [7]. It is also known that omalizumab treatment causes arteriothrombotic events. Myocardial infarction and stroke accounted for the majority of the omalizumab arterial thrombotic events $[11,12]$. Hypotension and flushing are uncommon side effects and rarely palpitations, tachycardia, sinus bradycardia have been reported $[7,13]$. There is limited data related to the use of omalizumab in elderly patients, and the side effects are similar to those experienced by younger patients [9]. The patient we presented here was 72 years old and had no complications after the first dose of omalizumab injection. However, high-ventricular response atrial fibrillation developed 6 hours after the second dose of omalizumab and there was no reason to trigger atrial fibrillation. This suggested that omalizumab may have been associated with atrial fibrillation and the treatment was discontinued.

\section{Conclusion}

Omalizumab has high efficacy and safety in patients with chronic spontaneous urticaria. However, different side effects related to biological treatments can be observed. Particular attention should be paid to the use of omalizumab in patients with arrhythmia. Patients should be monitored for longer periods in the hospital setting after omalizumab injection.

\section{References}

1. Zuberbier T, Aberer W, Asero R, Bindslev-Jensen C, Brzoza $\mathrm{Z}$, Canonica GW, et al. Methods report on the development of the 2013 revision and update of the EAACI/GA2 LEN/EDF/ WAO guideline for the definition, classification, diagnosis, and 
management of urticaria. Allergy. 2014;69:e1-e29.

2. Maurer M, Weller K, Bindslev-Jensen C, Giménez-Arnau A, Bousquet PJ, Bousquet $\mathrm{J}$, et al. Unmet clinical needs in chronic spontaneous urticaria. A GA2LEN task force report. Allergy. 2011;66:317-330.

3. Toubi E, Kessel A, Avshovich N, Bamberger E, Sabo E, Nusem $\mathrm{D}$, et al. Clinical and laboratory parameters in predicting chronic urticaria duration: a prospective study of 139 patients. Allergy. 2004;59:869-873.

4. Holgate ST, Djukanović R, Casale T, Bousquet J. Antiimmunoglobulin $\mathrm{E}$ treatment with omalizumab in allergic diseases: an update on anti-inflammatory activity and clinical efficacy. Clin Exp Allergy. 2005;35:408-416.

5. Bernstein JA, Lang DM, Khan DA, Craig T, Dreyfus D, Hsieh $\mathrm{F}$, et al. The diagnosis and management of acute and chronic urticaria: 2014 update. J Allergy Clin Immunol. 2014;133:12701277.

6. Kaplan A, Ledford D, Ashby M, Canvin J, Zazzali JL, Conner $\mathrm{E}$, et al. Omalizumab in patients with symptomatic chronic idiopathic/spontaneous urticaria despite standard combination therapy. J Allergy Clin Immunol. 2013;132:101-109.

7. Francés L, Leiva-Salinas M, Silvestre JF. Omalizumab in the treatment of chronic urticaria. Actas Dermosifiliogr. 2014;105:45-52.
8. Ali AK, Hartzema AG. Assesing the association between omalizumab and arteriothrombotic events through spontaneous adverse event reporting. J Asthma Allergy. 2012;5:1-9.

9. Nettis E, Cegolon L, Di Leo E, Canonica WG, Detoraki A, Italian OCUReL Study Group. Omalizumab in elderly patients with chronic spontaneous urticaria: An Italian real-life experience. Ann Allergy Asthma Immunol. 2018;120:318-323.

10. Cox L, Lieberman P, Wallace D, Simons FE, Finegold I, Platts-Mills T, et al. American Academy of Allergy, Asthma \& Immunology/American College of Allergy, Asthma \& Immunology omalizumab-associated anaphilaxis joint task force follow-up report. J Allergy Clin Immunol. 2011;128:210-212.

11. Medicines and Healthcare Regulatory Agency. Omalizumab: Potential risk of arterial thrombotic events.

12. Long AA, Fish JE, Rahmaoui A, Miller MK, Bradley MS, Taki HN, et al. Baseline characteristics of patients enrolled in EXCELS: a cohort study. Ann Allergy Asthma Immunol. 2009;103(3):212-219.

13. Savic S, Marsland A, McKay D, Ardern-Jones MR, Leslie $\mathrm{T}$, Somenzi O, et al. Retrospective case note review of chronic spontaneous urticaria outcomes and adverse effects in patients treated with omalizumab or ciclosporin in UK secondary care. Allergy Asthma Clin Immunol. 2015;11(1):21. 